\title{
Repeated outbreaks of Viral hemorrhagic fevers in Uganda
}

\author{
*Mbonye A, Wamala J, Kaboyo W, Tugumizemo V, Aceng J, Makumbi I
}

Ministry of Health Head Quarters, P.O Box 7272 Kampala, Uganda

\begin{abstract}
Background: Since the year 2000, Uganda has experienced repeated outbreaks of viral hemorrhagic fevers (VHF). Ebola VHF outbreak occurred in the districts of Gulu in 2000, Bundibugyo, 2007, Luwero, 2011, Kibaale in July 2012, Luwero in November 2012. Marburg VHF was earlier reported in Ibanda in 2007. More recently in 2012, two outbreaks of Marburg VHF have occurred in Ibanda and Kabale districts.

Objective: To present the epidemiological picture of the Marburg VHF recently reported in Ibanda and Kabale districts and propose research questions to generate evidence to mitigate future epidemics.

Methods: A case definition for a VHF was developed. A frequency distribution of symptoms of confirmed and probable cases was done. Descriptive analyses of reported cases using simple percentages, percent distributions and computation of means was performed.

Results: The Marburg epidemic was reported in early September and by November 2012, a cumulative of 14 cases (9 confirmed and 5 probable) including 7 deaths had been registered, giving a case fatality rate (CFR) of 50\%. A total of 202 contacts had been listed; out of which 193 had completed the 21-day follow-up period. The index case was a 33-year old male, a teacher at Nyakatukura Secondary School in Ibanda district. He travelled to Ibanda from Kabale, his home district on 31st August 2012, reportedly healthy. He fell sick on 3rd September 2012 with complaints of fever, headache, loss of appetite and general body weakness. Overall, the dominant symptoms for all cases were fever, vomiting, loss of appetite, headache, abdominal pain, fatigue, diarrhea, and the least in occurrence was bleeding which accounted for $35.5 \%$ of all the cases.

Conclusion: The source of infection for all the five Ebola Hemorrhagic fever outbreaks in Uganda and the recent Marburg VHF outbreak in Ibanda and Kabale is not known. Currently there is suspicion that there could be an animal reservoir of the Ebola and Marburg viruses from where occasional spillage into the human population occurs resulting in disease outbreaks. This and other hypotheses require further investigation.
\end{abstract}

Key words: viral hemorrhagic fevers, epidemics, Marburg, Ebola, Uganda

African Health Sciences 2012; 12(4): 579 - 583 http://dx.doi.org/10.4314/ahs.v12i4.31

\section{Background}

Viral Haemorrhagic Fever (VHF) such as Ebola and Marburg are caused by Filoviruses 1,2,3,4. There are four Ebola virus sub types that are pathogenic and naturally transmitted to humans, namely Ebola Zaire, Ebola Sudan, Ebola Bundibugyo and Ebola Ivory Coast. Since the year 2000, Uganda has documented a total of five outbreaks, of these four outbreaks were caused by Ebola Sudan and one outbreak of Ebola Bundibugyo occurred in 2007. Ebola

*Corresponding author:
Anthony Mbonye
Department of Community Health
Ministry of Health
P. O Box 7272
Kampala, Uganda
Email:vpadmn@infocom.co.ug,
akmbonye@yahoo.com

African Health Sciences Vol 12 Issue 4 December 2012 outbreaks have occurred in the districts of Gulu (2000), Bundibugyo (2007), Luwero (2011) $)^{5}$ and two outbreaks have occurred in the districts of Kibaale in July and Luwero in November this year ${ }^{6-14}$.

Two outbreaks of Marburg viral haemorrhagic fever have occurred in Uganda, the first in Ibanda (2007) and recently in Kabale district (2012). A foreign tourist was infected with the Marburg virus in December 2007 and another one in July 2008 after visiting python caves in Imaramagambo forest in current Rubirizi district. One of the tourist died abroad of Marburg fever in 2008 .

The current Marbug epidemic started as a cluster of deaths due to a strange illness reported to the district health office of Kabale on 16th October 2012. The reported deaths occurred in one family in Rwabirundo village, Kitumba parish, Kitumba sub- 
county. The district health office notified the Ministry of Health of the strange illness/cluster of deaths on the 18th October 2012. Three blood samples collected from the initial cases tested positive for Marburg at Uganda Virus Research Institute, Entebbe. To that effect, the Ministry of Health declared an outbreak of Marburg in Kabale district on the 19th October 2012.

In response to the outbreak, the Ministry of Health $(\mathrm{MoH})$ convened an emergency national taskforce meeting to initiate and coordinate control interventions to the outbreak. A national rapid response team comprising of experts from $\mathrm{MoH}$, UPDF, WHO, CDC, and AFENET was constituted and deployed to Kabale district on 19th October 2012 to conduct outbreak investigation and support district response.

\section{Methods}

Description of cases

The index case is suspected to be a 33-year old male, a teacher at Nyakatukura Secondary School in Ibanda district. He travelled to Ibanda from Kabale, his home district on 31st August 2012, reportedly healthy. He fell sick on 3rd September 2012 with complaints of fever, head ache, loss of appetite and general body weakness. He sought treatment from Ibanda Parents Clinic, Ibanda Town Council where he was treated for Malaria, typhoid fever, and Brucellosis. His illness continued worsening despite the treatment prompting him to return to Kabale district on 15th September 2012. He was admitted in Rugarama hospital on $17^{\text {th }}$ October 2012 where a provisional diagnosis of gastroenteritis with malaria was made. His condition continued deteriorating and he was referred to Kabale RRH on 19th September 2012 with a diagnosis of acute abdomen. He later on died on 20th September 2012 and was buried on 22nd September 2012. Prior to his death, he reportedly manifested with difficulty in breathing, difficulty in swallowing and bleeding from the gums. There were no significant pointers to the likely source of the infection.
Subsequently, the brother and mother to the initial case fell sick with similar illness on $25^{\text {th }}$ September 2012 and 30th September 2012 respectively. The two cases were admitted in Rugarama hospital from where the mother to the initial case died on 4th October 2012. The brother to the initial case referred himself to Kampala for further medical care where he sought for treatment from Kampala Medical Chambers. Following his recovery from the illness, a convalescent sample tested IgM positive for Marburg. Five other family members (two sisters, a brother, one maternal uncle, and a brother in-law) were affected with similar illness in the subsequent days, three of them eventually died. The second cluster in this outbreak is linked to a mortuary attendant who reportedly treated the body of the initial case. The mortuary attendant, a 32-year old male working in Kabale RRH developed illness on 2nd October 2012 and later died on 8th October 2012. Three other confirmed cases (the mother, the wife and the sister) are linked to the mortuary attendant; with the mother succumbing to the illness on 27th October 2012. The third cluster in this outbreak is linked to a lady Pastor who prayed for the brother and sister to the initial case. She tested positive for Marburg on PCR on 30th October 2012.

Another focus of Marburg viral disease was reported in Ibanda district following confirmation of three cases from one family in Sigirira village, Kihani parish, Kikyenkye sub-county in Ibanda district on 26th October 2012. No obvious epidemiological link has been established between the Ibanda foci and the clusters in Kabale. Investigations however are ongoing to determine if the outbreaks in Ibanda and Kabale are epidemiologically linked.

\section{Results \\ Cumulated cases}

As of 13th November 2012, a cumulative of 14 cases ( 9 confirmed and 5 probable) including 7 deaths have been registered, giving a case fatality rate (CFR) of $50 \%$. A total of 202 contacts have been listed; out of which 193 have completed the 21-day followup period.

Table 1: Case definition final outcome for all patients examined

\begin{tabular}{llll}
\hline Case definition & Total N (\%) & AliveN (\%) & DeadN (\%) \\
\hline Confirmed & $12(8.9 \%)$ & $8(66.7 \%)$ & $4(33.3 \%)$ \\
Probable & $5(3.7 \%)$ & $0(0.0 \%)$ & $5(100 \%)$ \\
Suspect & $11(8.2 \%)$ & $0(0.0 \%)$ & $11(100.0 \%)$ \\
Ruled Out & $107(79.3 \%)$ & $93(86.9 \%)$ & $14(13.1 \%)$ \\
\hline
\end{tabular}


Table 2: Laboratory status for all patients examined

\begin{tabular}{lll}
\hline Laboratory Status & Frequency & Percent \\
\hline Confirmed Acute & 4 & $3.0 \%$ \\
Confirmed Convalescent & 8 & $5.9 \%$ \\
Negative & 106 & $78.5 \%$ \\
Unable to Test & 6 & $4.4 \%$ \\
Results Pending (skin biopsies) & 11 & $8.1 \%$ \\
\hline
\end{tabular}



Figure 1: Epidemic curve for confirmed and probable cases by day of symptom onset

Table 3: Final outcome of confirmed and probable cases

\begin{tabular}{llll}
\hline Case definition status & AliveN (\%) & DeadN (\%) & Total N (\%) \\
\hline Confirmed \& Probable & $8(47.1 \%)$ & $9(52.9 \%)$ & 17 \\
\hline
\end{tabular}

Table 4: Gender distribution of confirmed and probable cases

\begin{tabular}{lll}
\hline Case definition status & Female N (\%) & Male N (\%) \\
\hline Confirmed & $7(58.3 \%)$ & $5(41.7 \%)$ \\
Probable & $2(40.0 \%)$ & $3(60.0 \%)$ \\
Total confirmed & $9(52.9 \%)$ & $8(47.1 \%)$ \\
and probable & & \\
\hline
\end{tabular}

Table 5: Select symptoms of confirmed and Probable cases

\begin{tabular}{lccl}
\hline Symptom & $\begin{array}{c}\text { Present } \\
\text { N (\%) }\end{array}$ & $\begin{array}{c}\text { Absent } \\
\mathbf{N ~ ( \% )}\end{array}$ & $\begin{array}{l}\text { Unknown } \\
\mathbf{N ~ ( \% )}\end{array}$ \\
\hline Fever & $16(94.1 \%)$ & $1(5.9 \%)$ & - \\
Vomiting & $14(82.4 \%)$ & $1(5.9 \%)$ & $2(11.8 \%)$ \\
Loss of appetite & $12(70.6 \%)$ & $3(17.6 \%)$ & $2(11.8 \%)$ \\
Headache & $12(70.6 \%)$ & $2(11.8 \%)$ & $3(17.6 \%)$ \\
Abdominal pain & $11(64.7 \%)$ & $2(11.8 \%)$ & $4(23.5 \%)$ \\
Fatigue & $11(64.7 \%)$ & $3(17.6 \%)$ & $3(17.6 \%)$ \\
Diarrhea & $8(47.1 \%)$ & $7(41.2 \%)$ & $2(11.8 \%)$ \\
Muscle/Joint pain & $6(35.3 \%)$ & $7(41.2 \%)$ & $4(23.5 \%)$ \\
Any bleeding & $6(35.3 \%)$ & $8(47.1 \%)$ & $3(17.6 \%)$ \\
\hline
\end{tabular}




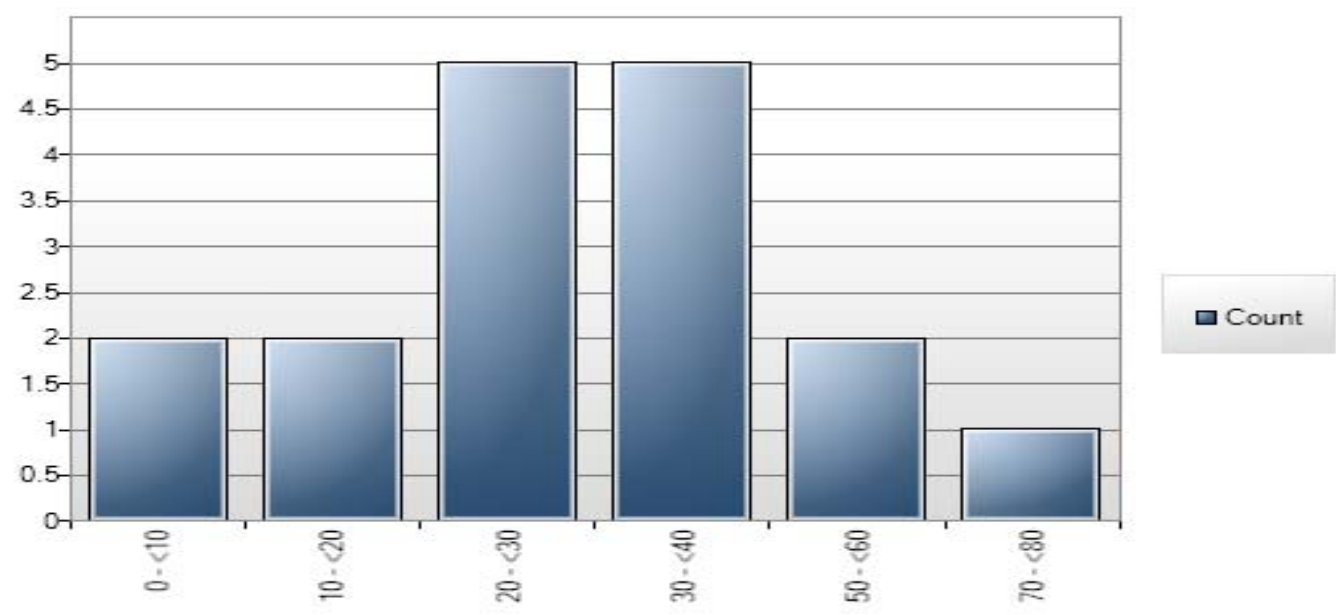

$*$ Mean Age $=30$ years $; *$ Minimum $=1.3$ years, Maximum $=70$ years

Figure 2: Age distribution of confirmed and probable

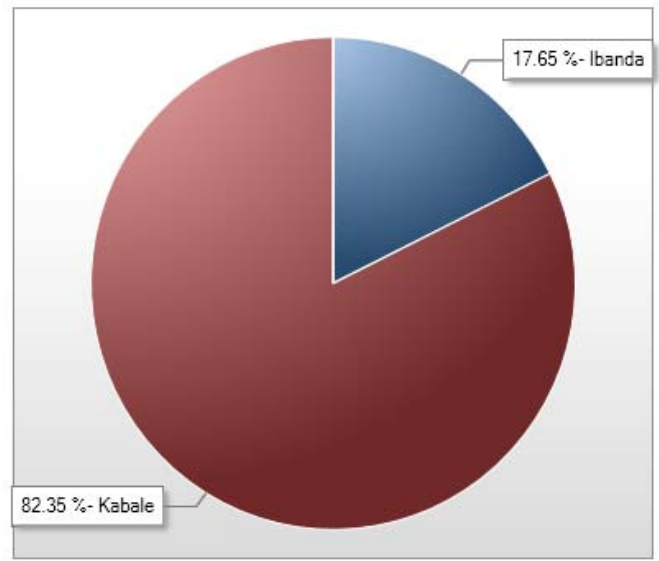

Figure 3: District of residence for confirmed and probable cases

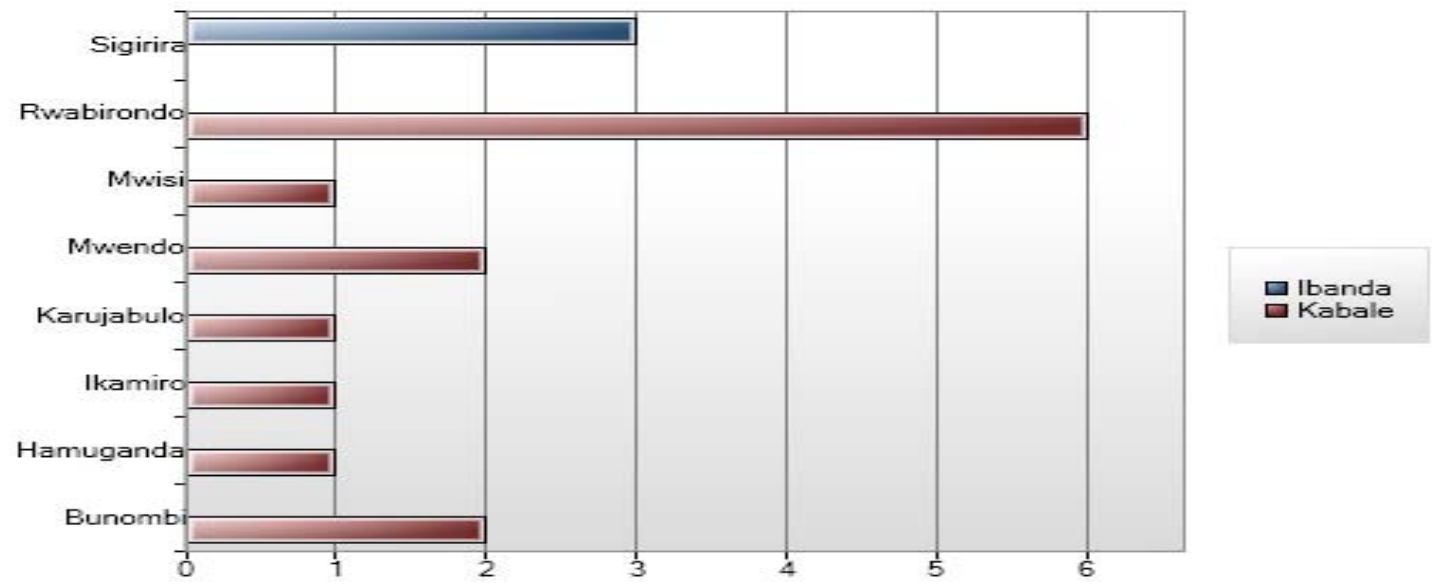

Figure 4: Village of residence for confirmed and probable cases 


\section{Discussion}

Uganda has experienced repeated out breaks of VHFs. The source of infection of the first (index) human case of Ebola Hemorrhagic fever outbreaks in all the five outbreaks in Uganda has never been conclusively determined. In the case of the current Marburg outbreak in Kabale the source of infection is yet to be conclusively documented. In the face of repeated epidemics hypotheses and research questions need to be formulated to guide research into the transmission chain of these epidemics.

The interaction between the viral agent, the host and the role of the environment need to be reexamined in setting up the hypotheses. For example has the Ebola/Marburg viral genome changed and able to infect many unknown hosts? Are we able to detect the infections through heightened surveillance activities? This could imply that the VHFs have been endemic in Uganda. What are the beliefs and perceptions surrounding these infections? Has human behaviour changed in the interaction with animals? Therefore it is imperative to urgently answer these and other questions in order to design appropriate actions to prevent and mitigate future VHF outbreaks.

Currently there is suspicion that there could be an animal reservoir of the Ebola and Marburg viruses from where occasional spillage into the human population occurs resulting in disease outbreaks. Evidence has been documented that fruit eating bats (Rousettus aegyptiacus) are carriers of the Marburg virus and could have been the source of Marburg HF to humans in 2007 and 2008. It is this linkage that the VHF ecological studies are expected to uncover by collecting and conducting laboratory analyses of blood and tissue samples from animals such as; nonhuman primates (e.g. monkeys, chimpanzees, baboons), bats, small rodents, warthogs and domestic animals such as pigs, dogs and small ruminants.

\section{Conclusion}

The repeated VHFs in Uganda require urgent attention. The $\mathrm{MOH}$ together with research institutions and development partners are discussing a research agenda that will contribute to mitigation of future VHF out breaks.

\section{References}

1. Borchert M, Mutyaba I, Van Kerkhove MD, Lutwama J, Luwaga H, Bisoborwa G, Turyagaruka J, Pirard P, Ndayimirije N, Roddy P, Van Der Stuyft

African Health Sciences Vol 12 Issue 4 December 2012
P. Ebola haemorrhagic fever outbreak in Masindi District, Uganda: outbreak description and lessons learned. BMC Infect Dis. 2011 Dec 28;11:357.

2. Muyembe-Tamfum JJ, Mulangu S, Masumu J, Kayembe JM, Kemp A, Paweska JT. Ebola virus outbreaks in Africa: Past and present. Onderstepoort J Vet Res. 2012 Jun 20;79(2):E1-8.

3. Callaway E. Ebola outbreak tests local surveillance. Nature. 2012 Aug 16;488(7411):265-6.

4. Outbreak news. Ebola haemorrhagic fever, Uganda - update. Wkly Epidemiol Rec. 2012 Dec 7;87(49/ 50):493.

5. Roddy P, Howard N, Van Kerkhove MD, Lutwama J, Wamala J, Yoti Z, Colebunders R, Palma PP, Sterk E, Jeffs B, Van Herp M, Borchert M. Clinical manifestations and case management of ebola haemorrhagic Fever caused by a newly identified virus strain, Bundibugyo, Uganda, 2007-2008. PLoS One. 2012;7(12):e52986.

6. Green A. Uganda battles Marburg fever outbreak. Lancet. 2012 Nov 17;380(9855):1726. No

7. Sobarzo A, Perelman E, Groseth A, Dolnik O, Becker S, Lutwama JJ, Dye JM, Yavelsky V, Lobel L, Marks RS. Profiling the native specific human humoral immune response to Sudan Ebola virus strain Gulu by chemiluminescence enzyme-linked immunosorbent assay. Clin Vaccine Immunol. 2012 Nov;19(11):1844-52.

8. Shoemaker T, MacNeil A, Balinandi S, Campbell S, Wamala JF, McMullan LK, Downing R, Lutwama J, Mbidde E, Ströher U, Rollin PE, Nichol ST. Reemerging Sudan Ebola virus disease in Uganda, 2011.Emerg Infect Dis. 2012 Sep;18(9):1480-3.

9. Wasswa H. Uganda gears up to contain Ebola epidemic as fears of spread cause panic. BMJ. 2012 Aug 1;345:e5210.

10. Kinsman J. "A time of fear": local, national, and international responses to a large Ebola outbreak in Uganda. Global Health. 2012 Jun 13;8:15.

11. Mwesiga A. Reporting epidemics: newspapers, information dissemination and the story of Ebola in the Ugandan district of Luweero. Pan Afr Med J. 2011;9:43.

12.Gupta M, MacNeil A, Reed ZD, Rollin PE, Spiropoulou CF. Serology and cytokine profiles in patients infected with the newly discovered Bundibugyo ebolavirus. Virology. $2012 \mathrm{Feb}$

13. Kortepeter MG, Bausch DG, Bray M. Basic clinical and laboratory features of filoviral hemorrhagic fever. J Infect Dis. 2011 Nov;204 Suppl 3:S810-6.

14. MacNeil A, Farnon EC, Morgan OW, Gould P, Boehmer TK, Blaney DD, Wiersma P, Tappero JW, Nichol ST, Ksiazek TG, Rollin PE. Filovirus outbreak detection and surveillance: lessons from Bundibugyo. J Infect Dis. 2011 Nov;204 Suppl 3:S761-7. 